\title{
BMJ Open Harms from other people's drinking: an international survey of their occurrence, impacts on feeling safe and legislation relating to their control
}

\author{
Mark A Bellis, ${ }^{1,2,3}$ Zara Quigg, ${ }^{3}$ Karen Hughes, ${ }^{3}$ Kathryn Ashton, ${ }^{1}$ Jason Ferris, ${ }^{4}$ \\ Adam Winstock ${ }^{5}$
}

To cite: Bellis MA, Quigg Z, Hughes $\mathrm{K}$, et al. Harms from other people's drinking: an international survey of their occurrence, impacts on feeling safe and legislation relating to their control. BMJ Open 2015;5:e010112. doi:10.1136/bmjopen-2015010112

\section{- Prepublication history} and additional material is available. To view please visit the journal (http://dx.doi.org/ 10.1136/bmjopen-2015010112).

Received 25 September 2015 Revised 12 October 2015 Accepted 13 October 2015

CrossMark

\section{${ }^{1}$ Public Health Wales, Cardiff, UK \\ ${ }^{2}$ College of Health and Behavioural Sciences, Bangor University, Bangor, UK \\ ${ }^{3}$ Centre for Public Health, Liverpool John Moores University, Liverpool, UK ${ }^{4}$ Institute for Social Science Research, The University of Queensland, Indooroopilly, Queensland, Australia \\ ${ }^{5}$ Institute of Psychiatry, King's College London, Camberwell, UK}

Correspondence to Professor Mark A Bellis; m.a.bellis@bangor.ac.uk

\section{ABSTRACT}

Objective: To examine factors associated with suffering harm from another person's alcohol consumption and explore how suffering such harms relate to feelings of safety in nightlife.

Design: Cross-sectional opportunistic survey (Global Drug Survey) using an online anonymous questionnaire in 11 languages promoted through newspapers, magazines and social media.

Subjects: Individuals (participating November 2014-January 2015) aged 18-34 years, reporting alcohol consumption in the past 12 months and resident in a country providing $\geq 250$ respondents ( $\mathrm{n}=21$ countries; 63725 respondents).

Main outcome measures: Harms suffered due to others' drinking in the past 12 months, feelings of safety on nights out (on the way out, in bars/pubs, in nightclubs and when travelling home) and knowledge of over-serving laws and their implementation.

Results: In the past 12 months, $>40 \%$ of respondents suffered at least one aggressive (physical, verbal or sexual assault) harm and $59.5 \%$ any harm caused by someone drunk. Suffering each category of harm was higher in younger respondents and those with more harmful alcohol consumption patterns. Men were more likely than women to have suffered physical assault $(9.2 \%$ vs $4.7 ; p<0.001)$, with women much more likely to suffer sexual assault or harassment ( $15.3 \%$ vs $2.5 \% ; p<0.001)$. Women were more likely to feel unsafe in all nightlife settings, with $40.8 \%$ typically feeling unsafe on the way home. In all settings, feeling unsafe increased with experiencing more categories of aggressive harm by a drunk person. Only $25.7 \%$ of respondents resident in countries with restrictions on selling alcohol to drunks knew about such laws and $75.8 \%$ believed that drunks usually get served alcohol.

Conclusions: Harms from others' drinking are a threat to people's health and well-being. Public health bodies must ensure that such harms are reflected in measures of the societal costs of alcohol, and must advocate for the enforcement of legislation designed to reduce such harms.

\section{Strengths and limitations of this study}

- The Global Drug Survey is an established survey that allows the collection of comparative data on alcohol and drug-related issues from a large international sample of individuals.

- The sample includes a high proportion of younger respondents who can be difficult to capture on telephone or in face-to-face surveys.

- The survey tool measures a unique combination of harms from others' drinking, their relationships with feelings of safety in nightlife situations, and respondents' knowledge and observations on aspects of alcohol legislation.

- While the sample size is large, participation is self-selected, and therefore, the sample should not be considered representative of any specific population.

- In studies of this design, reliability of responses cannot be confirmed, although previous audits of the survey suggest deliberate sabotage (ie, individuals submitting multiple completions) is not an issue.

\section{INTRODUCTION}

Globally, alcohol is estimated to result in 3.3 million deaths each year. Such deaths arise from over 200 disease and injury-related conditions, wholly or partly caused by consumption of alcohol. ${ }^{12}$ Research continues to add more conditions to this total with studies identifying and quantifying additional harms caused by alcohol not just to the drinkers themselves, but also to individuals affected by the drinking of others. ${ }^{1}{ }^{3}{ }^{4}$ Such harms include alcohol-related violence (eg, nightlife and domestic violence, elder and child abuse and neglect ${ }^{5}$ ), unintentional injury of others (eg, road traffic and work-place incidents $\left.^{6}\right)$, property damage ${ }^{7}$ and the toxic effects of alcohol transferring to others (ie, fetal harms through maternal alcohol 
consumption). ${ }^{8}$ Importantly, in addition to physical and toxic assault, drinkers can impose harms on others' mental health and well-being through, for example, fear of assault, concern for other people's safety, neglect or exploitation resulting from drinking by carers, and even disturbance to sleep. ${ }^{9}$ A survey on harms to others found that increased exposure to heavy drinkers was associated with lower levels of both well-being and health status. Moreover, the prevalence of such harms was higher $(18 \%)$ than harms from individuals' own drinking (12\%), especially among young people and women. ${ }^{10} 11$

A variety of studies have established that harms caused by others' drinking are common events. In a survey of Australian adults, $70 \%$ had been adversely affected by a stranger's drinking in the last year, with $30 \%$ affected by the drinking of someone they knew. ${ }^{12}$ A study in the USA indicated that $53 \%$ of individuals had experienced one or more harms from others' drinking over their life course. ${ }^{13}$ Other studies in Canada, Scotland, Norway and Ireland, ${ }^{3}{ }^{14-16}$ all identify high levels of harms from others' drinking, and while such studies are not directly comparable (ie, each measures different harms), together they demonstrate that this is an international phenomenon. The impact of such harms is also substantive. Estimates for the European Union suggest that 5564 men and 2147 women (aged 15-64 years) died as a result of other people's drinking in a single year. ${ }^{17}$ Such deaths represent only the tip of the iceberg; in Australia (2005), while 367 people died due to others' drinking, 14000 individuals were hospitalised, and an estimated 10.5 million suffered some negative effects. ${ }^{18}$ Although all demographic groups appear affected by harms from others' drinking, studies suggest such harms vary by both age and sex. Thus, women have been identified as suffering greater harms from others' drinking in private settings, and through family-related (eg, marital) problems ${ }^{19} 20$ with men at increased risk of physical assault. ${ }^{3}{ }^{19}$ Further, multiple studies have identified that younger individuals also suffer more harms as a result of others' drinking. ${ }^{15} 20$

While increasing numbers of countries are starting to administer local and national surveys of harms resulting from others' drinking, both descriptive epidemiology and understanding of effective measures of prevention require substantive development. Even where policy-level interventions have been established for decades (eg, legislation preventing the service of alcohol to inebriated individuals), research suggests that implementation is limited. ${ }^{21}{ }^{22}$ Consequently, WHO has identified research on harms to others from drinking as a key component in their Research Initiative on Alcohol, Health and Development. ${ }^{1}$

The Global Drug Survey (GDS) is a large, international, annual survey covering both alcohol and drug use which is self-completed largely by younger individuals on a self-nominating and anonymous basis. The 2015 iteration included a module of questions on harms resulting from other people's alcohol consumption. Using results from this module, this study examines the harms that respondents have suffered in the past 12 months as a result of others' drinking, and how these relate to respondents' own alcohol consumption. Focusing specifically on a subset of aggressive harms (physical, sexual and verbal assault), analyses explore how experiencing such harms from others' drinking relates to personal feelings of safety when going out to socialise. Finally, we explore whether respondents are aware of over-serving legislation developed to reduce harms associated with inebriation, and whether such legislation is enforced in their social environments.

\section{METHODS}

The GDS is an anonymous, online survey widely promoted in partnership with a range of media including national newspapers, magazines, web sites and social media outlets. ${ }^{23}$ The first iteration of the GDS collected data in 2011, and subsequently has been used to identify and explore emerging trends in drug and alcoholrelated harm. ${ }^{24}$ The most recent survey (GDS 2015) collected data during November 2014-January 2015, and was available in 11 languages (English, German, Greek, Polish, French, Italian, Spanish, Portuguese, Flemish, Hungarian and Danish). The sample was opportunistic and not intended to be representative of any specific population, but as it was a self-selected sample, those with social interests in alcohol and/or drugs are likely to be over-represented. Other publications provide further details on the utility, design and limitations of the GDS. ${ }^{23}{ }^{25}{ }^{26}$ At the point of analysis for this study, 89509 completions of GDS 2015 were available for inclusion. However, in order to utilise a more defined data set, analyses were limited to those aged 18-34 years, reporting gender (men or women), who had consumed alcohol in the past 12 months and were resident in a country, contributing at least 250 responses to the survey (see online supplementary table $A, n=21$ countries). The final sample size was, therefore, $\mathrm{n}=63725(71.2 \%$ of all available completions).

The GDS includes extensive substance use screening questions measuring the types and quantities of licit and illicit drugs consumed. ${ }^{23}$ However, analyses within this study focus on measures of alcohol use and a range of questions on harms from others' drinking, feeling of safety on nights out, and both knowledge and implementation of laws to prevent drunkenness in countries of residence (here, sales to inebriated individuals). For alcohol, respondents completed the Alcohol Use Disorders Identification Test (AUDIT) questionnaire that collects measures of drinking levels, dependence and harms. ${ }^{27}$ Respondents were rated in score categories of $0-7,8-15,16-19$ and $20+$, hereon referred to as lower risk, increasing risk, higher risk and possible dependence, respectively. Harms due to others' drinking are measured through the questions 'In the past 12 months 
have you been negatively affected by someone else's drinking in any of the following ways: (1) physically assaulted by someone who was drunk; (2) sexually harassed or assaulted by someone who was drunk; (3) called names or insulted by someone who was drunk; (4) injured accidentally by someone who was drunk; (5) had property damaged by someone who was drunk; (6) involved in a traffic accident caused by a drunk driver or pedestrian and (7) kept awake by drunken noise. A combined aggressive harms category for anyone experiencing physical (1), sexual (2) or verbal (3) harms from others' drinking was created to examine how experiencing such aggressive actions may impact feelings of safety when on a night out. Feelings of safety on a night out were measured using separate Likert scales ( $1=$ very unsafe to $5=$ very safe) for: on the way out; in bars/pubs; in nightclubs; and travelling home after a night out. In order to specifically examine impressions of low safety, respondents were categorised as feeling very unsafe/ unsafe (score 1 or 2) or safer (score 3-5). Finally, respondents were asked if it was illegal for servers to sell alcohol to drunk people in their country, and whether they thought someone who was obviously drunk would usually be served alcohol.

Demographics included in analyses were age (categorised as 18-24, 25-29, 30-34 years), sex, country of residence and basic educational attainment (whether respondents had at least a high school/secondary school education; here used as a socioeconomic proxy). ${ }^{28}$ Preliminary data exploration examined potential duplicate responses. Across demographics combined with key variables used in analyses here, $0.7 \%(n=467)$ of respondents had a response set identical to at least one other respondent. Whether these were duplicate responses or different individuals could not be established. However, these levels were considered low enough to not substantively affect findings and, consequently, such cases were retained in the data. As the sample was opportunistic, analyses focused on exploring relationships between demographics, harms from others' drinking and other variables of interest at the individual respondent level. Thus, $\chi^{2}$ and logistic regression modelling were used to identify and quantify the strength of associations between such variables. All such analyses were undertaken in SPSS (V.21).

\section{RESULTS}

In both genders, prevalence of all types of harms from others' drinking is highest in the age category of 18-24 years and reduces with age (table 1). Being verbally insulted was the most frequent harm for both men and women. Men were nearly twice as likely as women to report being physically assaulted by someone drunk in the past 12 months, with over 1 in 10 men aged 18-24 years having suffered such an assault. By contrast, women were over six times more likely than men to have been sexually assaulted or harassed by someone drunk (table 1). Over 1 in 6 women aged 18-24 years had suffered such sexual harassment in the past 12 months. A combined aggressive harms category including any physical, sexual or verbal assault in the past 12 months (table 1) identified that over $40 \%$ of respondents had suffered at least one such assault; although overall prevalence did not differ between sexes (table 1). For other harms, women were substantively more likely to suffer unintended injury and being kept awake, and men were marginally more likely to report property damage (table 1). The least frequently reported harm was from a traffic incident where only men age 18-24 years exceeded $1 \%$ in the past 12 months. Nearly 6 in 10 respondents reported at least one negative impact of others' drinking in the past 12 months (table 1).

Respondents' alcohol consumption (AUDIT score) was strongly related to their risk of suffering harms from others' drinking (table 2). Each individual category of harm increased with increasing AUDIT score category. Thus, risks of physical assault by someone drunk were over five times higher in possible dependence versus lower risk drinking categories (table 2). Respondents with lower educational attainment were more likely to report suffering physical assault, unintended injury and traffic incidents as a result of others' drinking, but less likely to report sexual assault/harassment or being kept awake (table 2). Using logistic regression modelling to control for demographic confounders (table 3; online supplementary table B), younger age remained strongly associated with higher risks of all harms from others' drinking along with higher AUDIT categories. Men were significantly more likely to experience physical assault, verbal insult, traffic incident and property damage due to someone else's drinking in the past 12 months, with women at higher risk from sexual assault/harassment, unintentional injury and being kept awake (table 3). Having a high school education reduced the odds of experiencing physical assault, unintentional injury, traffic incident and property damage, but increased the odds of being kept awake.

Overall, the proportion of respondents feeling unsafe/very unsafe on a night out in their country of residence increases from $4.9 \%$ while in bars, to $28.6 \%$ on the way home (table 4). Using logistic regression modelling to control for demographic confounders (table 5; online supplementary table $\mathrm{C}$ ), feeling unsafe was more frequently reported in all settings by women, those without a high school education, and younger age groups (apart from in bars). For alcohol consumption, respondents with the lowest AUDIT scores were most likely to feel unsafe in bars and nightclubs, but both lowest and highest AUDIT categories felt more unsafe on the way out and way home (table 5). Experiencing more categories of harms from others' drinking in the past 12 months was associated with feeling unsafe in all settings (tables 4 and 5). Thus, feeling unsafe on the way home rises from $25.8 \%$ of those experiencing no harms to $46.5 \%$ of those experiencing harms in all three 


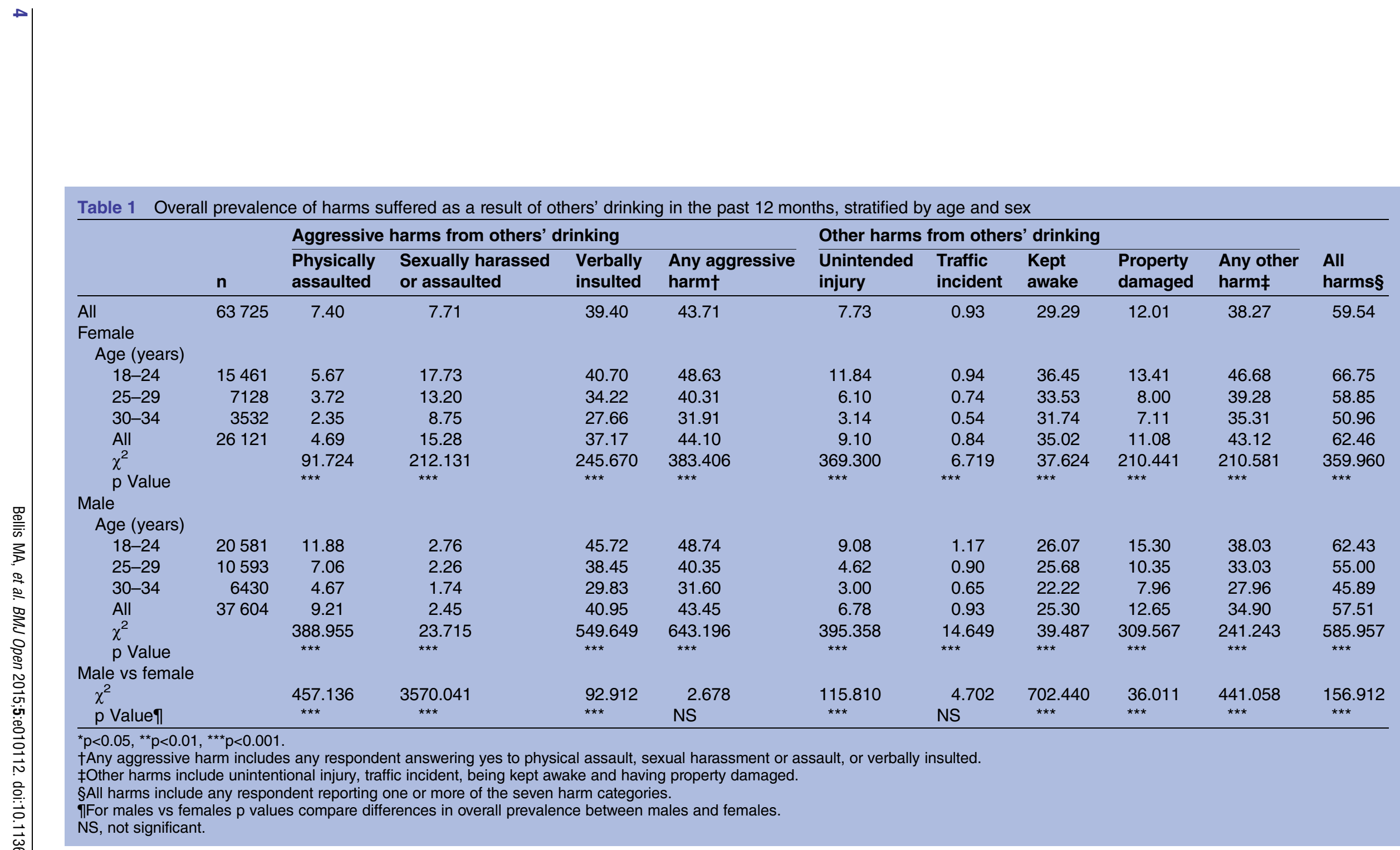




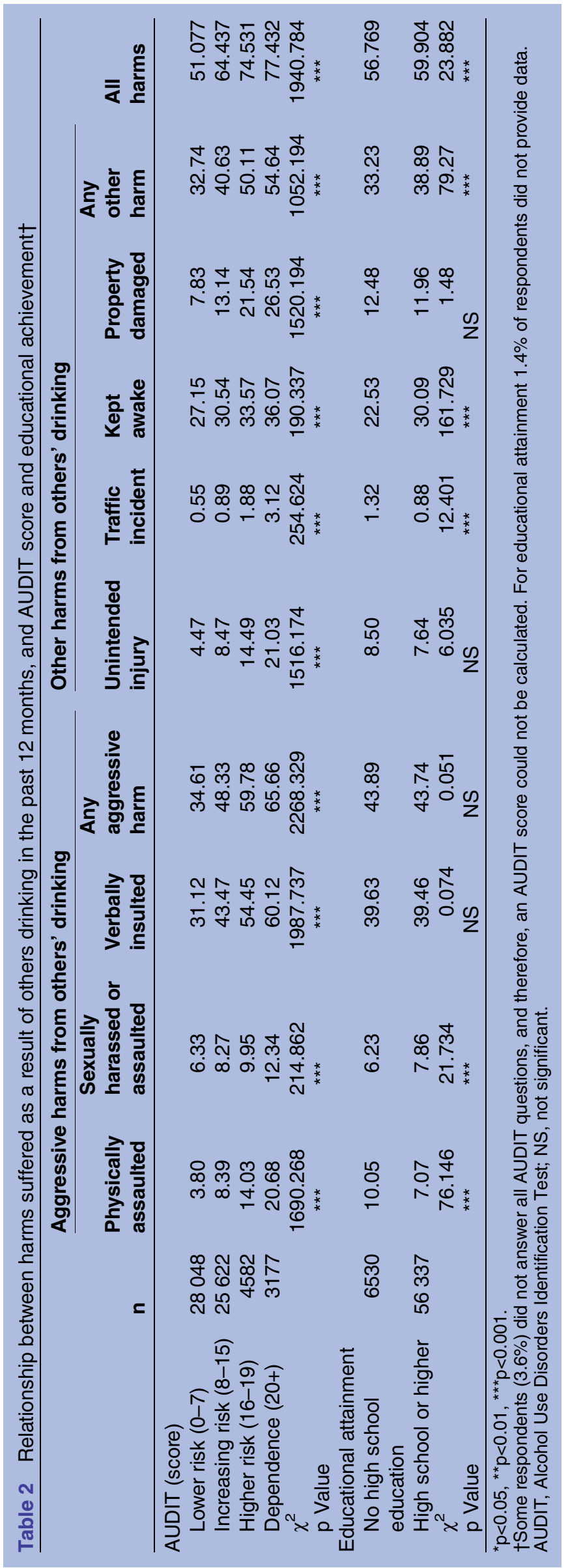

aggressive categories (physically assaulted, sexually harassed/assaulted, verbally insulted) in the past 12 months (table 4).

Finally, knowledge of laws to prevent extreme drunkenness and its consequences through prohibiting sale of alcohol to already inebriated individuals were examined. On the basis of data from the Global Status Report on Alcohol and Heath, ${ }^{1}$ sales to inebriated individuals are prohibited in 19 of the 21 countries included here (see supplementary table A). However, only a quarter of respondents (25.7\%) from these 19 countries knew about such restrictions (see online supplementary table $\mathrm{A}$; vs $8.8 \%$ of respondents from the two countries without legislation believing restrictions were in place, $\left.\chi^{2}=620.181, \mathrm{p}<0.001\right)$. Across all 19 countries with restrictions more than three-quarters of respondents $(75.8 \%)$ believed that drunks usually get served alcohol, which was marginally more than in countries with no such restriction $\left(71.3 \% ; \chi^{2}=44.040, \mathrm{p}<0.001\right)$. At a country level, there is a strong correlation between proportions in a country thinking it is illegal to be served alcohol when drunk, and the proportion identifying that drunks are not usually served $\left(\mathrm{R}^{2}=0.326, \mathrm{p}=0.004\right)$.

\section{DISCUSSION}

The 2030 Agenda for Sustainable Development commits all countries in the United Nations to Sustainable Development Goals that include: making cities safe; halving deaths and injuries from road traffic accidents; and reducing all forms of violence with particular emphasis on violence against women and girls. ${ }^{29}$ Critically, global definitions of violence and sexual violence include both threat and use of physical force, as well as their impacts on physical or psychological harm. ${ }^{30}$ Our study found that harms caused by others' drinking routinely impact on the safety, well-being (table 2) and feelings of security (table 4) of substantive numbers of young respondents. In total, $9.2 \%$ of men and $4.7 \%$ of women surveyed reported being physically assaulted by someone who was drunk, and over one in seven women had been sexually assaulted or harassed by a drunk person in the past 12 months (table 1). While the severity of such events was not recorded here, results elsewhere identify alcohol as a major component in the perpetration of sexual violence including rape. ${ }^{31}$ Moreover, as with other surveys, other harms that may be considered relatively minor were substantively more common (eg, 29.3\% kept awake by drunken noise).${ }^{9} 10$ Evidence indicates that such harms, even on an occasional basis, may impact health and quality of life. ${ }^{32}$

While suffering harms from others' drinking varied with age, sex and educational status, respondents' own alcohol consumption patterns also affected risk (tables 2 and 3). Higher risk drinkers had odds of being physically assaulted by an intoxicated individual 5.8 times higher than those in the lower risk category. Unintended injury by a drunk, and harms from a traffic 
Table 3 Logistic regression model for AUDIT score and demographic relationships with harms suffered as a result of others' drinking in the past 12 months

\begin{tabular}{|c|c|c|c|c|c|c|c|c|c|c|c|c|c|c|c|c|c|c|c|c|}
\hline & \multicolumn{8}{|c|}{ Aggressive harms from others' drinking } & \multicolumn{10}{|c|}{ Other harm from others' drinking } & & \\
\hline & \multicolumn{2}{|c|}{ Physically assaulted } & \multicolumn{2}{|c|}{$\begin{array}{l}\text { Sexually harassed } \\
\text { or assaulted }\end{array}$} & \multicolumn{2}{|c|}{ Verbally insulted } & \multicolumn{2}{|c|}{$\begin{array}{l}\text { Any aggressive } \\
\text { harm }\end{array}$} & \multicolumn{2}{|c|}{ Unintended injury } & \multicolumn{2}{|l|}{ Traffic incident } & \multicolumn{2}{|l|}{ Kept awake } & \multicolumn{2}{|c|}{ Property damaged } & \multicolumn{2}{|c|}{ Any other harm } & \multicolumn{2}{|l|}{ All harms } \\
\hline & $\begin{array}{l}\text { AOR } \\
(95 \% \text { Cls })\end{array}$ & $\begin{array}{l}\mathbf{p} \\
\text { Value }\end{array}$ & $\begin{array}{l}\text { AOR } \\
\text { (95\% Cls) }\end{array}$ & $\begin{array}{l}\mathbf{p} \\
\text { Value }\end{array}$ & $\begin{array}{l}\text { AOR } \\
(95 \% \text { Cls) }\end{array}$ & $\begin{array}{l}\mathbf{p} \\
\text { Value }\end{array}$ & $\begin{array}{l}\text { AOR } \\
(95 \% \text { Cls) }\end{array}$ & $\begin{array}{l}\mathbf{p} \\
\text { Value }\end{array}$ & $\begin{array}{l}\text { AOR } \\
(95 \% \mathrm{Cls})\end{array}$ & $\begin{array}{l}p \\
\text { Value }\end{array}$ & $\begin{array}{l}\text { AOR } \\
\text { (95\% Cls) }\end{array}$ & $\begin{array}{l}\mathbf{p} \\
\text { Value }\end{array}$ & $\begin{array}{l}\text { AOR } \\
\text { (95\% Cls) }\end{array}$ & $\begin{array}{l}\mathbf{p} \\
\text { Value }\end{array}$ & $\begin{array}{l}\text { AOR } \\
(95 \% \text { Cls) }\end{array}$ & $\begin{array}{l}\mathbf{p} \\
\text { Value }\end{array}$ & $\begin{array}{l}\text { AOR } \\
(95 \% \text { Cls) }\end{array}$ & $\begin{array}{l}\mathbf{p} \\
\text { Value }\end{array}$ & $\begin{array}{l}\text { AOR } \\
\text { (95\% Cls) }\end{array}$ & $\begin{array}{l}\mathbf{p} \\
\text { Value }\end{array}$ \\
\hline \multicolumn{21}{|l|}{ Age (years) $\dagger$} \\
\hline $25-29$ & $\begin{array}{l}0.64 \\
(0.59 \text { to } 0.69)\end{array}$ & $* \star \star$ & $\begin{array}{l}0.79 \\
(0.73 \text { to } 0.85)\end{array}$ & $\star \star \star *$ & $\begin{array}{l}0.77 \\
(0.74 \text { to } 0.80)\end{array}$ & $* \star *$ & $\begin{array}{l}0.74 \\
\text { (0.71 to } 0.77)\end{array}$ & $* \star \star *$ & $\begin{array}{l}0.54 \\
(0.50 \text { to } 0.58)\end{array}$ & $* * *$ & $\begin{array}{l}0.89 \\
(0.73 \text { to } 1.09)\end{array}$ & NS & $\begin{array}{l}1.04 \\
(1.00 \text { to } 1.09)\end{array}$ & NS & $\begin{array}{l}0.67 \\
(0.63 \text { to } 0.71)\end{array}$ & 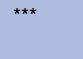 & $\begin{array}{l}0.86 \\
(0.82 \text { to } 0.89)\end{array}$ & 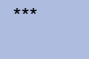 & $\begin{array}{l}0.78 \\
(0.75 \text { to } 0.81)\end{array}$ & 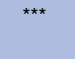 \\
\hline 30-34 & $\begin{array}{l}0.42 \\
(0.38 \text { to } 0.47)\end{array}$ & $* \star *$ & $\begin{array}{l}0.53 \\
\text { (0.47 to } 0.59 \text { ) }\end{array}$ & 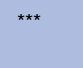 & $\begin{array}{l}0.56 \\
(0.53 \text { to } 0.59)\end{array}$ & $\star \star *$ & $\begin{array}{l}0.53 \\
(0.50 \text { to } 0.55)\end{array}$ & $* \star *$ & $\begin{array}{l}0.32 \\
(0.28 \text { to } 0.36)\end{array}$ & $* * *$ & $\begin{array}{l}0.63 \\
(0.47 \text { to } 0.84)\end{array}$ & ** & $\begin{array}{l}0.88 \\
(0.84 \text { to } 0.93)\end{array}$ & $\star \star \star \star ⿱ 乛 ⿻ 上 丨$ & $\begin{array}{l}0.55 \\
(0.51 \text { to } 0.60)\end{array}$ & ${ }^{* \star *}$ & $\begin{array}{l}0.70 \\
(0.66 \text { to } 0.73)\end{array}$ & ${ }^{* \star *}$ & $\begin{array}{l}0.56 \\
(0.54 \text { to } 0.59)\end{array}$ & $* \star \star$ \\
\hline \multicolumn{21}{|l|}{ Sex‡ } \\
\hline Male & $\begin{array}{l}1.94 \\
(1.80 \text { to } 2.08)\end{array}$ & ${ }^{* \star *}$ & $\begin{array}{l}0.13 \\
(0.12 \text { to } 0.14)\end{array}$ & $* \star *$ & $\begin{array}{l}1.13 \\
(1.09 \text { to } 1.17)\end{array}$ & $* \star *$ & $\begin{array}{l}0.92 \\
\text { (0.89 to } 0.95)\end{array}$ & $* * \star$ & $\begin{array}{l}0.68 \\
\text { (0.64 to } 0.72)\end{array}$ & $\star \star *$ & $\begin{array}{l}1.10 \\
\text { (0.92 to } 1.32)\end{array}$ & NS & $\begin{array}{l}0.66 \\
(0.64 \text { to } 0.68)\end{array}$ & $* \star \star *$ & $\begin{array}{l}1.16 \\
\text { (1.10 to } 1.22)\end{array}$ & ${ }^{* \star *}$ & $\begin{array}{l}0.71 \\
\text { (0.69 to } 0.74)\end{array}$ & ${ }^{* \star *}$ & $\begin{array}{l}0.78 \\
(0.75 \text { to } 0.81)\end{array}$ & $* \star \star *$ \\
\hline \multicolumn{21}{|l|}{ High school§ } \\
\hline Yes & $\begin{array}{l}0.72 \\
(0.65 \text { to } 0.79)\end{array}$ & $* * *$ & $\begin{array}{l}1.07 \\
(0.95 \text { to } 1.20)\end{array}$ & NS & $\begin{array}{l}0.95 \\
(0.90 \text { to } 1.01)\end{array}$ & NS & $\begin{array}{l}0.95 \\
(0.90 \text { to } 1.01)\end{array}$ & NS & $\begin{array}{l}0.78 \\
(0.70 \text { to } 0.86)\end{array}$ & $* * *$ & $\begin{array}{l}0.63 \\
(0.49 \text { to } 0.81)\end{array}$ & $* \star \star$ & $\begin{array}{l}1.29 \\
(1.21 \text { to } 1.38)\end{array}$ & $\star * \star$ & $\begin{array}{l}0.91 \\
(0.83 \text { to } 0.99)\end{array}$ & * & $\begin{array}{l}1.13 \\
(1.06 \text { to } 1.20)\end{array}$ & ${ }^{\star \star \star}$ & $\begin{array}{l}1.04 \\
(0.98 \text { to } 1.10)\end{array}$ & NS \\
\hline \multicolumn{21}{|c|}{ AUDIT scoreף } \\
\hline $\begin{array}{l}\text { Increasing } \\
\text { risk }\end{array}$ & $\begin{array}{l}2.08 \\
(1.92 \text { to } 2.25)\end{array}$ & $* \star *$ & $\begin{array}{l}1.63 \\
\text { (1.52 to } 1.75)\end{array}$ & *** & $\begin{array}{l}1.65 \\
\text { (1.59 to } 1.71)\end{array}$ & $* \star *$ & $\begin{array}{l}1.74 \\
\text { (1.68 to } 1.81)\end{array}$ & $* \star *$ & $\begin{array}{l}1.89 \\
\text { (1.75 to } 2.03)\end{array}$ & $\star \star \star *$ & $\begin{array}{l}1.51 \\
\text { (1.23 to } 1.87)\end{array}$ & $* * *$ & $\begin{array}{l}1.13 \\
(1.09 \text { to } 1.18)\end{array}$ & $* * *$ & $\begin{array}{l}1.65 \\
(1.55 \text { to } 1.75)\end{array}$ & $* * *$ & $\begin{array}{l}1.35 \\
(1.30 \text { to } 1.40)\end{array}$ & $* \star \star$ & $\begin{array}{l}1.69 \\
\text { (1.63 to } 1.75)\end{array}$ & 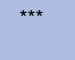 \\
\hline \multirow{2}{*}{ Higher risk } & $\begin{array}{l}3.60 \\
\text { (3.23 to } 4.00)\end{array}$ & ${ }^{* \star *}$ & $\begin{array}{l}2.17 \\
\text { (1.92 to } 2.44)\end{array}$ & $* \star \star$ & $\begin{array}{l}2.56 \\
\text { (2.40 to } 2.74)\end{array}$ & $\star \star * *$ & $\begin{array}{l}2.78 \\
\text { (2.60 to } 2.97)\end{array}$ & $* \star \star$ & $\begin{array}{l}3.33 \\
(3.00 \text { to } 3.70)\end{array}$ & $* \star \star$ & $\begin{array}{l}3.10 \\
(2.35 \text { to } 4.07)\end{array}$ & 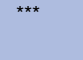 & $\begin{array}{l}1.25 \\
(1.16 \text { to } 1.34)\end{array}$ & 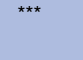 & $\begin{array}{l}2.90 \\
(2.66 \text { to } 3.16)\end{array}$ & ${ }^{* \star *}$ & $\begin{array}{l}1.92 \\
(1.80 \text { to } 2.06)\end{array}$ & ${ }^{\star \star \star}$ & $\begin{array}{l}2.71 \\
\text { (2.52 to } 2.92)\end{array}$ & *** \\
\hline & 5.80 & 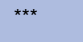 & 2.90 & 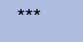 & 3.26 & *** & 3.62 & $\star \star \star *$ & 5.17 & $* \star *$ & 5.27 & 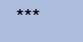 & & $* \star \star$ & & $* * *$ & & $\star \star \star ~$ & 3.13 & *** \\
\hline Dependence & (5.20 to 6.48$)$ & & (2.55 to 3.30$)$ & & (3.02 to 3.52$)$ & & (3.34 to 3.92$)$ & & (4.64 to 5.75 ) & & (4.05 to 6.85$)$ & & (1.21 to 1.42$)$ & & (3.41 to 4.11 ) & & (2.05 to 2.40$)$ & & (2.87 to 3.43 ) & \\
\hline \multicolumn{21}{|c|}{$\begin{array}{l}\text { Country of residence was also included in the logistic regression model and AORs for countries are included in online supplementary table } B \text {. } \\
{ }^{*} p<0.05,{ }^{* *} p<0.01,{ }^{* *} p<0.001 . \\
+18-24 \text { years. } \\
\text { fFemale. } \\
\text { §Did not attend high school. } \\
\text { qLower risk. }\end{array}$} \\
\hline
\end{tabular}


Table 4 Variations by sociodemographics and AUDIT category in proportions of respondents feeling unsafe/very unsafe at different points of a night out

\begin{tabular}{|c|c|c|c|c|}
\hline & \multicolumn{4}{|c|}{ Feel unsafe or very unsafe $†$} \\
\hline & On way out & In bars & In nightclubs & On way home \\
\hline $\mathrm{n}$ & 62851 & 62610 & 61010 & 62321 \\
\hline All & 6.83 & 4.90 & 14.41 & 28.59 \\
\hline \multicolumn{5}{|l|}{ Age (years) } \\
\hline $18-24$ & 7.51 & 5.03 & 15.24 & 32.20 \\
\hline $25-29$ & 6.00 & 4.61 & 13.75 & 25.13 \\
\hline 30-34 & 5.84 & 4.95 & 12.56 & 21.75 \\
\hline$\chi^{2}$ & 59.653 & 4.559 & 51.526 & 549.68 \\
\hline p Value & $\star * *$ & NS & $\star * *$ & $\star * *$ \\
\hline \multicolumn{5}{|l|}{ Gender } \\
\hline Female & 9.15 & 5.98 & 17.10 & 40.80 \\
\hline Male & 5.21 & 4.15 & 12.55 & 20.16 \\
\hline$\chi^{2}$ & 369.738 & 109.193 & 247.676 & 3144.88 \\
\hline p Value & *** & 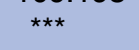 & $* \star *$ & $* * * *$ \\
\hline \multicolumn{5}{|l|}{ Education } \\
\hline No high school & 7.82 & 7.39 & 17.58 & 27.58 \\
\hline High school or higher & 6.73 & 4.60 & 14.00 & 28.68 \\
\hline$\chi^{2}$ & 10.729 & 95.152 & 57.091 & 3.398 \\
\hline $\mathrm{p}$ Value & 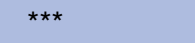 & 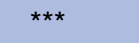 & $\star \star \star ~$ & NS \\
\hline \multicolumn{5}{|l|}{ AUDIT (score) } \\
\hline Lower risk (0-7) & 7.09 & 5.96 & 16.58 & 28.90 \\
\hline Increasing risk (8-15) & 6.27 & 3.77 & 12.36 & 27.15 \\
\hline Higher risk (16-19) & 6.87 & 3.60 & 12.32 & 28.91 \\
\hline Dependence $(20+)$ & 7.62 & 4.84 & 14.55 & 35.34 \\
\hline$\chi^{2}$ & 18.181 & 153.236 & 202.818 & 96.71 \\
\hline p Value & 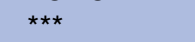 & $* * *$ & $* * * *$ & $* * *$ \\
\hline \multicolumn{5}{|c|}{ Aggressive harms from others' drinking count‡ } \\
\hline 0 & 6.49 & 4.76 & 13.09 & 25.75 \\
\hline 1 & 7.09 & 4.71 & 14.96 & 30.64 \\
\hline 2 & 7.57 & 5.88 & 19.13 & 36.59 \\
\hline 3 & 10.30 & 10.33 & 26.75 & 46.52 \\
\hline$\chi^{2}$ & 26.92 & 58.664 & 235.704 & 458.033 \\
\hline p Value & $* * *$ & 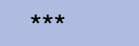 & 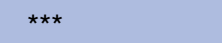 & 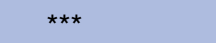 \\
\hline
\end{tabular}

incident caused by someone else's drinking were also more than five times more likely in higher risk drinkers (vs lower risk drinkers). In part, those identifying heavy or problematic drinking in their own behaviour may also be more likely to acknowledge that harms from others result from the drunken state of such individuals. However, our findings are consistent with those elsewhere, suggesting that risks of suffering harm from others' drinking increase in those who themselves drink more. ${ }^{3}{ }^{16}$ While the GDS study could not identify causality, a number of factors link heavy alcohol consumption and increased harms from others' drinking. Thus, heavy drinkers have a reduced ability to recognise warning signs of, and so avoid, potentially violent or dangerous situations; may visit settings patronised by heavy drinkers more often; or may themselves drink heavily to cope with harms they already suffer from a drunk (eg, living with an abusive or neglectful drinker). ${ }^{33-35}$ Raising people's awareness of how their own heavy drinking may make them more vulnerable to harms from other drinkers could encourage behavioural change but is poorly explored as a public health intervention.

Attempts to better control alcohol misuse often focus on the harms drinkers cause to themselves with harms to others being neglected. ${ }^{12}$ Consequently, accusations of 'nanny states' are raised by the alcohol industry insinuating that governments interfere with choices that individuals should make about their own health. ${ }^{36}$ However, this ignores the legitimate role that governments have in ensuring individuals are protected from harms caused by others' drinking, and how poorly controlled alcohol promotion, pricing and access 
Table 5 Logistic regression analysis of factors associated with feeling unsafe/very unsafe $\dagger$ at different times during a night out

\begin{tabular}{|c|c|c|c|c|c|c|c|c|c|c|c|c|}
\hline & \multicolumn{3}{|c|}{ On way out } & \multicolumn{3}{|c|}{ In bars } & \multicolumn{3}{|c|}{ In nightclubs } & \multicolumn{3}{|c|}{ On way home } \\
\hline & $\overline{\text { AOR }}$ & $95 \% \mathrm{Cls}$ & p Value & $\overline{\text { AOR }}$ & $95 \%$ Cls & p Value & AOR & $95 \%$ Cls & p Value & $\overline{\text { AOR }}$ & $95 \%$ Cls & p Value \\
\hline \multicolumn{13}{|l|}{ Age (years) $\ddagger$} \\
\hline $25-29$ & 0.84 & 0.78 to 0.91 & $* \star \star$ & 0.93 & 0.85 to 1.02 & NS & 0.92 & 0.87 to 0.97 & $\star \star$ & 0.74 & 0.71 to 0.78 & $* * *$ \\
\hline $30-34$ & 0.84 & 0.76 to 0.93 & $* * *$ & 1.04 & 0.93 to 1.16 & NS & 0.82 & 0.77 to 0.88 & $* * *$ & 0.64 & 0.61 to 0.68 & $\star * *$ \\
\hline \multicolumn{13}{|l|}{ Sex§ } \\
\hline Male & 0.55 & 0.51 to 0.58 & 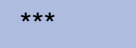 & 0.73 & 0.68 to 0.79 & $* * *$ & 0.75 & 0.71 to 0.79 & $\star \star \star *$ & 0.35 & 0.33 to 0.36 & $\star \star \star$ \\
\hline \multicolumn{13}{|l|}{ High schooln } \\
\hline Yes & 0.62 & 0.55 to 0.69 & $\star \star \star *$ & 0.49 & 0.44 to 0.55 & $* * *$ & 0.64 & 0.60 to 0.70 & $\star \star \star *$ & 0.75 & 0.70 to 0.80 & $\star \star \star$ \\
\hline \multicolumn{13}{|l|}{ AUDIT (score) ${ }^{\star \star}$} \\
\hline Increasing risk & 0.84 & 0.78 to 0.91 & $* * *$ & 0.62 & 0.56 to 0.67 & $* \star \star$ & 0.68 & 0.65 to 0.72 & $* * *$ & 0.87 & 0.84 to 0.91 & $\star * *$ \\
\hline Higher risk & 0.87 & 0.76 to 0.99 & * & 0.56 & 0.47 to 0.66 & $* \star \star$ & 0.65 & 0.59 to 0.72 & 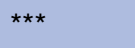 & 0.89 & 0.82 to 0.96 & $\star \star$ \\
\hline Dependence & 0.86 & 0.74 to 1.00 & NS & 0.65 & 0.54 to 0.78 & $* * *$ & 0.71 & 0.63 to 0.79 & $* * *$ & 1.10 & 1.01 to 1.20 & * \\
\hline \multicolumn{13}{|c|}{ Aggressive harms from others' drinking count†† } \\
\hline 1 & 1.25 & 1.16 to 1.34 & *** & 1.15 & 1.06 to 1.26 & ** & 1.28 & 1.21 to 1.35 & $* * *$ & 1.36 & 1.30 to 1.41 & 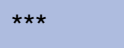 \\
\hline 2 & 1.44 & 1.28 to 1.63 & $* \star \star$ & 1.58 & 1.38 to 1.81 & *** & 1.77 & 1.63 to 1.92 & 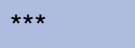 & 1.77 & 1.66 to 1.90 & $\star \star \star *$ \\
\hline 3 & 2.00 & 1.54 to 2.61 & $\star \star \star *$ & 2.97 & 2.28 to 3.86 & $\star * *$ & 2.60 & 2.17 to 3.11 & $\star \star \star *$ & 2.30 & 1.95 to 2.72 & $\star \star \star *$ \\
\hline
\end{tabular}

Aggressive harms from others' drinking count are the total number of harm categories reported from; physically assaulted, sexually harassed or assaulted and verbally insulted.

Country of residence was also included in the logistic regression model and AORs (adjusted ORs) for countries are included in online supplementary table C.

${ }^{\star} p<0.05,{ }^{* *} p<0.01,{ }^{* * *} p<0.001$.

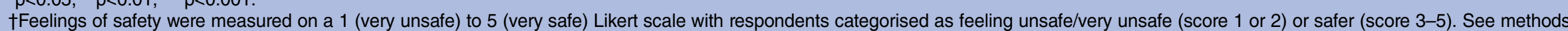
for more details.

$\ddagger 18-24$ years.

$\S$ Female.

IDid not attend high school.

${ }^{* *}$ Lower risk.

††0.

AOR, adjusted OR; AUDIT, Alcohol Use Disorders Identification Test; NS, not significant. 
undermine this role. ${ }^{37} 38$ Here, in an international sample, over $40 \%$ of female respondents felt unsafe or very unsafe on the way home after a night out (table 4). The vast majority of respondents were from high-income countries where legislation, problem-orientated policing, and environmental adaptations such as lighting, pedestrianisation and reliable public transport should provide safety and security even in the early hours of the morning. However, respondents' fears are largely justified. In England and Wales, for instance, 53\% of the 1.3 million violent incidents occurring in the year 2013/ 2014 were alcohol-related, increasing to $64 \%$ of those when the assailant was a stranger and $84 \%$ of those between midnight and 6:00. ${ }^{39}$

Feeling unsafe, or very unsafe, on the way out, in bars and nightclubs, and on the way home, all increased substantively with the number of aggressive harms respondents had suffered through others' drinking (limited to physically assaulted, sexually harassed/assaulted, verbally insulted; tables 4 and 5). How much such feelings actually impact on individuals' choices to go out at all, or only visit selected destinations was not measured here. However, feelings of safety have been identified as a key issue in choice of both tourism destinations ${ }^{40}$ and nights out in an individual's country of residence, with, for example, a survey of around 30000 individuals in England finding that nearly half the individuals avoided their local town or city centre at night because of the drunken behaviour of others. ${ }^{41}$ Consequently, while some licensed venues in nightlife settings may thrive on unrestricted sales to individuals regardless of their drunken state, ${ }^{42}$ other businesses including restaurants and better-regulated bars and clubs are likely to be losing potential customers.

Links between inebriation and increased risks of disturbance, including committing violence, have been documented since at least ancient Egyptian times, ${ }^{43}$ and legislation aimed at protecting the peace, through preventing alcohol sales to those already drunk, can date back centuries. ${ }^{44}$ However, despite 19 of the 21 countries included in these analyses having laws restricting sales of alcohol to drunks, only $25.7 \%$ of respondents in these countries knew about the laws (see online supplementary table A). Further, over three-quarters of respondents from these countries thought that inebriated individuals would usually be served alcohol. Legislation relating to serving drunks can play an important role in reducing harms in nightlife, with promotion of its use already reported as both effective and cost-effective in the reduction of antisocial behaviour. ${ }^{21}{ }^{45}$ Some countries are now using such legislation on a regular basis (eg, Finland and Sweden ${ }^{46}{ }^{47}$ ). However, results here suggest that, internationally, there is an urgent need to increase both public and hospitality industry awareness, and critically enforce the legislation of over-serving of alcohol.

The study has a number of important limitations. Respondents were from an opportunistic sample and should not be considered representative of any country or region. Consequently, analyses have focused on predictors of harms from others' drinking and feelings of safety at an individual respondent level rather than establishing measures of population prevalence in any country. Further, the sample was also limited to those who had consumed alcohol in the previous 12 months. Therefore, the impact of harms that others' drinking had on abstainers, while an important consideration, was not captured in these analyses. Our data provided only one general measure of socioeconomic status (here, high school educational attainment). However, while it suggested a protective impact of higher socioeconomic status on experiencing some harms (eg, physical assault; table 3) and increased feeling of safety when out (table 5), it can only be considered a rough socioeconomic proxy. Questions were also limited to whether respondents had experienced harms at all and, therefore, levels of severity were not available for analysis. Moreover, we cannot rule out the impact of recall bias or deliberate misreporting on results. Finally, as an online questionnaire, it is possible that the same individual completed the form multiple times. However, $<1 \%$ of the sample provided identical response sets across demographics and key variables used in these analyses. This is consistent with previous audits of the GDS. ${ }^{26}$

\section{CONCLUSIONS}

This study adds further international evidence to a growing body of studies that both identify high levels of harms resulting from other people's drinking, and provide the necessary methodologies to quantify them. ${ }^{48}$ Despite such evidence, harms from, for instance, violence committed by drunk individuals, are frequently omitted from estimates of alcohol-attributable burdens of disease. ${ }^{1}$ They are, however, a critical part of establishing the right balance between individuals' rights to consume alcohol and the responsibilities of governments to protect individuals from the harms drinkers may cause others. The 2030 Agenda for Sustainable Development connects violence and insecurity with poor governance, and calls for nations to strengthen the prevention and treatment of the harmful use of alcohol. ${ }^{29}$ Results here suggest that harms from others' drinking are a common threat to people's health and well-being, that large proportions of individuals (especially women) feel unsafe returning from a night out even in developed countries, and that legislation developed, in part, to tackle such issues is typically ignored. Public health bodies must ensure that harms caused by others' drinking are fully reflected in measures of the societal costs of alcohol, and through partnership with other public sector bodies, that legislation is effectively communicated and enforced.

Contributors AW and JF developed and directed the survey. MAB, KH and AW conceived and designed the survey questions on violence and alcohol. JF coordinated data collection and cleaning. MAB performed the statistical analyses and drafted the manuscript. ZQ, KH and KA contributed to the 
literature review, and all authors drafted, edited and approved the fina manuscript.

Funding Global Drug Survey Ltd is an independent self-funded survey. The authors received no financial support for the preparation and/or publication of this article.

Competing interests AW is the founder and owner of Global Drug Survey. JF is part of the Global Drug Survey Expertise Advisory Committee.

Ethics approval The Psychiatry, Nursing and Midwives Ethics subcommittee at Kings College, London.

Provenance and peer review Not commissioned; externally peer reviewed.

Data sharing statement No additional data are available.

Open Access This is an Open Access article distributed in accordance with the Creative Commons Attribution Non Commercial (CC BY-NC 4.0) license, which permits others to distribute, remix, adapt, build upon this work noncommercially, and license their derivative works on different terms, provided the original work is properly cited and the use is non-commercial. See: http:// creativecommons.org/licenses/by-nc/4.0/

\section{REFERENCES}

1. World Health Organization. Global status report on alcohol and health 2014. Geneva: World Health Organization, 2014. http://www. who.int/substance_abuse/publications/global_alcohol_report/en/ (accessed 24 Aug 2015).

2. Jones L, Bellis MA. Updating England-specific alcohol-attributable fractions. Liverpool: Centre for Public Health, Liverpool John Moores University, 2014. http://www.cph.org.uk/publication/updating-englandspecific-alcohol-attributable-fractions/ (accessed 24 Aug 2015).

3. Hope A. Alcohol's harm to others in Ireland. Dublin: Health Service Executive, 2014. http://www.hse.ie/eng/services/Publications/topics/ alcohol/ah2o.html (accessed 24 Aug 2015).

4. Laslett AM, Callinan S, Mugavin J, et al. Beyond the drinker: longitudinal patterns in alcohol's harm to others. Canberra: Foundation for Alcohol Research and Education, 2015. http://www. fare.org.au/2015/03/beyond-the-drinker-longitudinal-patterns-inalcohols-harm-to-others/ (accessed 24 Aug 2015).

5. Bellis MA, Hughes K, Hughes S, et al. Policy briefing: interpersonal violence and alcohol. Geneva: World Health Organization, 2006. http://www.who.int/violence_injury_prevention/violence/world_report/ factsheets/en/ (accessed 24 Aug 2015).

6. Waller PF, Hill EM. Alcohol effects on motor vehicle crash injury. Alcohol Clin Exp Res 2003;27:695-703.

7. Stevenson RJ, Lind B, Weatherburn D. Property damage and public disorder: their relationship with sales of alcohol in New South Wales Australia. Drug Alcohol Depend 1999;54:163-70.

8. Morleo M, Woolfall K, Dedman D, et al. Under-reporting of foeta alcohol spectrum disorders: an analysis of hospital episode statistics. BMC Pediatr 2011;11:14.

9. Laslett AM, Room R, Ferris J, et al. Surveying the range and magnitude of alcohol's harm to others in Australia. Addiction 2011;106:1603-11.

10. Casswell S, Harding JF, You RQ, et al. Alcohol's harm to others: self-reports from a representative sample of New Zealanders. N Z Med J 2011;124:75-84.

11. Connor J, Casswell S. Alcohol-related harm to others in New Zealand: evidence of the burden and gaps in knowledge. $N Z M e d J$ 2012;125:11-27.

12. Room R, Ferris J, Laslett AM, et al. The drinker's effect on the socia environment: a conceptual framework for studying alcohol's harm to others. Int J Environ Res Public Health 2010;7:1855-71.

13. Greenfield TK, Karriker-Jaffe KJ, Giesbrecht N, et al. Second-hand drinking may increase support for alcohol policies: new results from the 2010 National Alcohol Survey. Drug Alcohol Rev 2014;33:259-67.

14. Adlaf EM, Begin P, Sawka E, eds. Canadian addiction survey (CAS): a national survey of Canadians' use of alcohol and other drugs: prevalence of use and related harms: detailed report. Ottawa: Canadian Centre on Substance Abuse, 2005. http://www.ccsa.ca/ Resource\%20Library/ccsa-004028-2005.pdf (accessed 8 Sep 2015).

15. Gell L, Ally A, Buykx P, et al. Alcohol's harm to others: a report for the institute of alcohol studies produced by the University of Sheffield School of Health and Related Research (ScHARR). Sheffield: Institute of Alcohol Studies, 2015. http://www.ias.org.uk/
uploads/pdf/IAS\%20reports/rp18072015.pdf (accessed 24 Aug 2015).

16. Rossow I, Hauge R. Who pays for the drinking? Characteristics of the extent and distribution of social harms from others' drinking. Addiction 2004;99:1094-102.

17. Shield KD, Rylett MJ, Gmel G, et al. Part 1. Trends in alcohol consumption and alcohol-attributable mortality in the EU in 2010. In: World Health Organization Regional Office for Europe, eds. Status report on alcohol and health in 35 European countries. Copenhagen: WHO Regional Office for Europe, 2013:3-14.

18. Laslett $\mathrm{AM}$, Catalano $\mathrm{P}$, Chikritzhs $\mathrm{T}$, et al. The range and magnitude of alcohol's harm to others. Fitzroy: AER Centre for Alcohol Policy Research, Turning Point Alcohol and Drug Centre, Eastern Health, 2010. http://www.turningpoint.org.au/site/DefaultSite/ filesystem/documents/Centre\%20Publications/other\%20resources/ RangeMagnitudeAlcoholsHarmtoOthers_TechReport.pdf (accessed 24 Aug 2015).

19. Karriker-Jaffe KJ, Greenfield TK. Gender differences in associations of neighbourhood disadvantage with alcohol's harms to others: a cross-sectional study from the USA. Drug Alcohol Rev 2014;33:296-303.

20. Huhtanen $P$, Tigerstedt $C$. Women and young adults suffer most from other people's drinking. Drug Alcohol Rev 2012;31:841-6.

21. Norstrom T, Trolldal B. Was the STAD programme really that successful? Nordic Alcohol Drugs 2013;30:171-8.

22. Hughes $\mathrm{K}$, Bellis MA, Leckenby $\mathrm{N}$, et al. Does legislation to prevent alcohol sales to drunk individuals work? Measuring the propensity for night-time sales to drunks in a UK city. J Epidemiol Community Health 2014:68:453-6.

23. Global Drug Survey. 2015. http://www.globaldrugsurvey.com (accessed 24 Aug 2015).

24. Winstock AR, Mitcheson L, Gillatt DA, et al. The prevalence and natural history of urinary symptoms among recreational ketamine users. BJU Int 2012;110:1762-6.

25. Winstock A, Lynskey M, Borschmann R, et al. Risk of emergency medical treatment following consumption of cannabis or synthetic cannabinoids in a large global sample. J Psychopharmacol 2015;29:698-703

26. Barratt M, Ferris JA, Winstock AR. Use of Silk Road, the online drug marketplace, in the United Kingdom, Australia and the United States. Addiction 2014;109:774-83.

27. Babor T, Higgins-Biddle J, Saunders J, et al. AUDIT. The alcoho use disorders identification test. Guidelines for use in primary care. 2nd edn. Geneva: World Health Organization, 2001. http://www.who. int/substance abuse/publications/alcohol/en/ (accessed 24 Aug 2015).

28. Goodman A, Gregg P, eds. Poorer children's educational attainment how important are attitudes and behaviour? York: Joseph Rowntree Foundation, 2010. http://www.jrf.org.uk/publications/educationalattainment-poor-children (accessed 24 Aug 2015)

29. Sustainable Development Knowledge Platform. Transforming our world: the 2030 Agenda for Sustainable Development. 2015. https:// sustainabledevelopment.un.org/post2015/transformingourworld (accessed 24 Aug 2015).

30. World Health Organization. World report on violence and health: summary. Geneva: World Health Organization, 2002. http://www. who.int/violence injury prevention/violence/world report/en/ summary_en.pdf (accessed 24 Aug 2015)

31. Abbey A, Zawacki T, Buck PO, et al. Sexual assault and alcohol consumption: what do we know about their relationship and what types of research are still needed? Aggress Violent Behav 2004:9:271-303.

32. Kahn M, Fridenson S, Lerer R, et al. Effects of one night of induced night-wakings versus sleep restriction on sustained attention and mood: a pilot study. Sleep Med 2014;15:825-32.

33. Graham K. Social drinking and aggression. In: Mattson M, ed Neurobiology of aggression: understanding and preventing violence. 1st edn. Totowa, NJ, Humana Press, 2003:253-74.

34. Hughes K, Quigg Z, Bellis MA, et al. Drunk and disorganised: relationships between bar characteristics and customer intoxication in European drinking environments. Int J Environ Res Public Health 2012;9:4068-82.

35. Leadley K, Clark CL, Caetano R. Couples' drinking patters, intimate partner violence, and alcohol-related partnership problems. J Subst Abuse 2000;11:253-63.

36. Babor T, Hall W, Humphreys $\mathrm{K}$, et al. Who is responsible for the public's health? The role of alcohol industry in the WHO global strategy to reduce the harmful use of alcohol. Addiction 2013;108: 2045-7.

37. Holmes J, Meng Y, Meier PS, et al. Effects of minimum unit pricing for alcohol on different income and socioeconomic groups: a modelling study. Lancet 2014;383:1655-64. 
38. Livingston M. Alcohol outlet density and assault: a spatial analysis. Addiction 2008;103:619-28.

39. Flatley J. Crime statistics, focus on violence crime and sexual offences, 2013/14. London: Office for National Statistics, 2015. http://www.ons.gov.uk/ons/rel/crime-stats/crime-statistics/focus-onviolent-crime-and-sexual-offences-2013-14/index.html (accessed 02 Sep 2015).

40. Sirakaya E, Sheppard AG, McLellan RW. Assessment of the relationship between perceived safety at a vacation site and destination choice decisions: extending the behavioral decision-making model. J Hosp Tourism Res 1997; 21:1-10.

41. Cook $\mathrm{P}$, Tocque K, Morleo M, et al. Opinions on the impact of alcohol on individuals and communities: early summary findings from the North West Big Drink Debate. Liverpool: Centre for Public Health, Liverpool John Moores University, 2008. http://www.nwph. net/Publications/BDD.pdf (accessed 9 Sep 2015).

42. Bellis M, Hughes K, Quigg Z, et al. Cross-sectional measures and modelled estimates of blood alcohol levels in UK nightlife and their relationships with drinking behaviours and observed signs of inebriation. Subst Abuse Treat Prev Policy 2010;5:5.

43. El-Guebaly N, El-Guebaly A. Alcohol abuse in ancient Egypt: the recorded evidence. Int J Addict 1981;16:7.

44. Jennings P. Policing drunkenness in England and Wales from the late eighteenth century to the First World War. Soc Hist Alcohol Drugs 2012;26:69-92.

45. Jones L, Hughes $\mathrm{K}$, Atkinson $\mathrm{A}$, et al. Reducing harm in drinking environments: a systematic review of effective approaches. Health Place 2011:17:508-18.

46. Warpenius $\mathrm{K}$, Holmila $\mathrm{M}$, Mustonen $\mathrm{H}$. Effects of a community intervention to reduce the serving of alcohol to intoxicated patrons. Addiction 2010;105:1032-40.

47. Andreasson S, Lindewald B, Rehnman C. Over-serving patrons in licensed premises in Stockholm. Addiction 2000;95:359-63.

48. Shield KD, Gmel G, Patra J, et al. Global burden of injuries attributable to alcohol consumption in 2004: a novel way of calculating the burden of injuries attributable to alcohol consumption Popul Health Metr 2012;10:9. 